\title{
PMD Monitoring using Optical Sideband Filtering
}

\author{
Petersen, Martin Nordal; Sambo, N; Andriolli, N; Scaffardi, M
}

Published in:

IEEE LEOS Annual Meeting Conference Proceedings, 2009. LEOS '09.

Link to article, DOI:

10.1109/LEOS.2009.5343078

Publication date:

2009

Document Version

Publisher's PDF, also known as Version of record

Link back to DTU Orbit

Citation (APA):

Petersen, M. N., Sambo, N., Andriolli, N., \& Scaffardi, M. (2009). PMD Monitoring using Optical Sideband Filtering. In IEEE LEOS Annual Meeting Conference Proceedings, 2009. LEOS '09. IEEE.

https://doi.org/10.1109/LEOS.2009.5343078

\section{General rights}

Copyright and moral rights for the publications made accessible in the public portal are retained by the authors and/or other copyright owners and it is a condition of accessing publications that users recognise and abide by the legal requirements associated with these rights.

- Users may download and print one copy of any publication from the public portal for the purpose of private study or research.

- You may not further distribute the material or use it for any profit-making activity or commercial gain

- You may freely distribute the URL identifying the publication in the public portal

If you believe that this document breaches copyright please contact us providing details, and we will remove access to the work immediately and investigate your claim. 


\title{
PMD Monitoring using Optical Sideband Filtering
}

\author{
M. N. Petersen ${ }^{(1)}$, N. Sambo ${ }^{(2)}$, N. Andriolli ${ }^{(2)}$, M. Scaffardi ${ }^{(3)}$ \\ (1) DTU Fotonik ,Technical University of Denmark, 2800 Lyngby, Denmark. Email: mnpe@fotonik.dtu.dk \\ ${ }^{(2)}$ Scuola Superiore Sant'Anna, Pisa, Italy; ${ }^{(3)} \mathrm{CNIT}$, Pisa, Italy
}

\begin{abstract}
This paper presents a simple PMD monitoring technique based on optical sideband filtering, which requires no change to the transmitter. The method is numerically and experimentally verified and tested in a realtime PMD monitoring experiment.
\end{abstract}

\section{Introduction}

Polarisation Mode Dispersion (PMD) has been identified as one of the important sources of signal distortion in modern high-speed optical communication systems ${ }^{1}$. With the increased interest on more transparent optical networks, PMD is getting more attention due to accumulation of the effect through optically switched paths in the network. As the size of the optical transparent network grows, the statistical possibility of having a situation with detrimental PMD effects grows. Furthermore, since PMD has a statistical nature it is impossible to foresee the instant DGD value on a particular link and PMD monitoring therefore becomes necessary in order to assure signal integrity.

Various methods of PMD monitoring based on different technologies have been developed ${ }^{2,3}$. Some of these require the signal format to be return-to-zero $(R Z)^{4}$ while others require alterations being made to the transmitter ${ }^{5}$

This paper reports on a PMD monitoring technique that does not require any alterations made to the transmitter and also supports the commonly used non-return-to-zero (NRZ) modulation format. The method is based on optical side-band filtering of the optical spectrum, which is broadened from selfphase-modulation (SPM) effects due to pulse shape changes caused by $1^{\text {st }}$ order PMD. Experiments validating the technique have been carried out using $10 \mathrm{~Gb} / \mathrm{s} \mathrm{NRZ}$ data. Also, results from a long-term PMD monitoring experiment showing the method in use are presented. The experimental results are supported by numerical simulations carried out using Virtual Photonics Transmission maker VPI 8.0.

Principle of Operation and Experimental Setup This PMD monitoring technique exploits the effects of SPM induced spectral broadening in a non-linear medium due to high signal peak power ${ }^{6}$. Since PMD changes the shape of the optical pulse(s) any change due to PMD can be observed as a change in the optical spectrum. The degree of spectral broadening is dependant on SPM and the effect can be increased by utilizing a highly-non-linear-fibre (HNLF). Using a narrow optical filter the momentary changes can in turn be quantified and used as a $1^{\text {st }}$ order PMD monitor signal.

The graph in Fig. 1 shows the effect of PMD, introduced with a PMD emulator, on the optical spectrum recorded after the HNLF. In the top of Fig. 1 is shown a diagram/setup explaining the concept of the PMD monitoring technique.

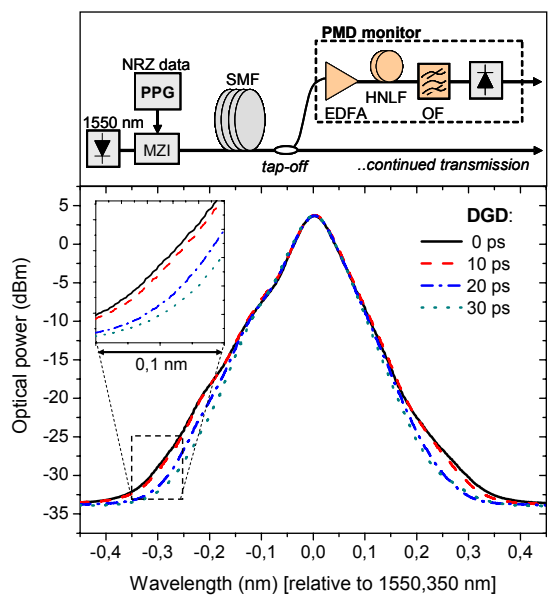

Fig. 1. Setup and concept of PMD monitoring using sideband filtering of PMD-SPM induced spectral broadening. The spectrum is experimentally achieved using a $10 \mathrm{~Gb} / \mathrm{s}$ NRZ signal.

The influence of the differential-group-delay (DGD) on the spectrum can be clearly observed from the figure. The $0.1 \mathrm{~nm}$ enlarged window of the spectrum illustrates the optical filtering at $-0.2 \mathrm{~nm}(-25 \mathrm{GHz})$ respective to the carrier at $1550.350 \mathrm{~nm}$.

The experimental setup consisted of a tuneable laser, Mach-Zehnder E/O modulator and a PPG creating the optical $10 \mathrm{~Gb} / \mathrm{s}$ NRZ signal with a PRBS of $2^{31}-1$. A spool of 10 year aged SMF fibre was available as PMD source. After transmission, a part of the PMD influenced signal was tapped off and sent to the PMD monitor, which is comprised of a EDFA with $23 \mathrm{dBm}$ fixed output power, $1.0 \mathrm{~km}$ HNLF and a Gaussian optical filter with a $3 \mathrm{~dB}$ bandwidth of $0.1 \mathrm{~nm}$. The slight detuning $(-0.2 \mathrm{~nm})$ of the optical filter is important in order to obtain a monitoring signal with high dynamic range. A simple power meter was used to read out the amount of filtered optical power. As will be seen in the next section, a $1^{\text {st }}$ order PMD emulator was used to calibrate the monitor in order to be able to convert the monitor signal into a PMD value. It should be noted that only $1^{\text {st }}$ order PMD (DGD) is monitored using this technique. $2^{\text {nd }}$ order PMD is generally considered of less influence and can, for a majority of applications, be disregarded ${ }^{7}$. 


\section{Experimental and numerical results}

To verify the validity of the PMD monitoring method a $1^{\text {st }}$ order PMD emulator from JDS Uniphase was used in the setup described above. While changing the DGD imposed on the signal, the monitor signal was recorded and the result can be seen in Fig. 2a. As expected, the spectral broadening and therefore also the monitor signal is reduced when the DGD increases. This is expected since the DGD causes a reduction in the peak power which in turn controls the level of SPM and spectral broadening.
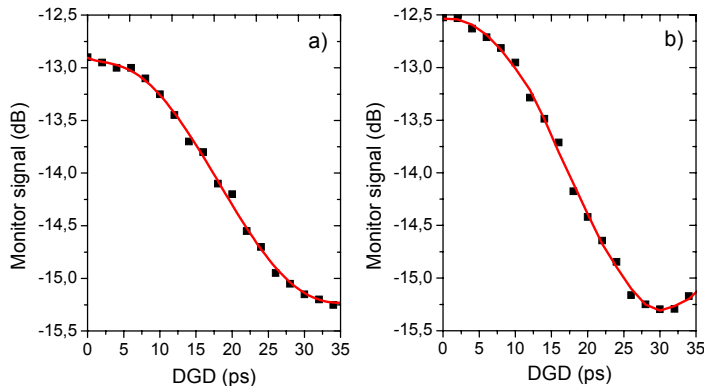

Fig. 2. Monitoring signal versus DGD for a) experiments and b) numerical simulations. Both are for a $10 \mathrm{~Gb} / \mathrm{s}$ NRZ signal and $0.1 \mathrm{~nm}$ optical filtering bandwidth

The same was done numerically using VPI 8.0 and the result of the simulations can be seen in Fig. $2 \mathrm{~b}$. In both the experimental and numerical trials the bit rate was $10 \mathrm{~Gb} / \mathrm{s}$ NRZ and the $0.1 \mathrm{~nm}$ Gaussian filter was detuned $-0.2 \mathrm{~nm}$ respective to the carrier at 1550.35 $\mathrm{nm}$. Comparing Fig. $2 \mathrm{a}$ ) and b) it is evident that the predictions of the behaviour from the numerical simulations are fulfilled also in the experimental case. Using the monitor signal, the above results thus give us a one-to-one measurement of the $1^{\text {st }}$ order PMD in the region from 0 to $\sim 33$ ps. Beyond 33 ps DGD a single monitor signal cannot assure a full injective curve, which means that the monitored link or network should not give rise to DGD values above this value. This problem can be however solved with two distinct monitoring signals, obtained by simply filtering at two positions. For each position of the optical filter generating the monitor signal, a different curve is observed with a different minimum. This in turn gives the required information to deduce the DGD, also for DGD values beyond $33 \mathrm{ps}$.

Since 30 ps DGD corresponds to $1 \mathrm{~dB}$ power penalty for a $10 \mathrm{~Gb} / \mathrm{s} \mathrm{NRZ}$ signal, it was in these trials assumed to be a sufficient dynamic range.

In order to further test the usefulness of the PMD monitoring method reported here, a real-time trial was conducted using a 10 years old span of $80 \mathrm{~km} \mathrm{SMF}$ fibre. The PMD of the fibre has previously been asserted to be around 6-8 ps. In order to further increase the PMD variations, the fibre spool was inserted into a temperature controlled chamber and cooled to $5^{\circ} \mathrm{C}$ and after three hours re-heated to $22^{\circ} \mathrm{C}$. This treatment causes stress in the fibre and increases the PMD of the fiber ${ }^{8}$ allowing us to observed stronger variations within a relative short time frame. Fig. 3 below shows the result from the real-time PMD monitoring trial.

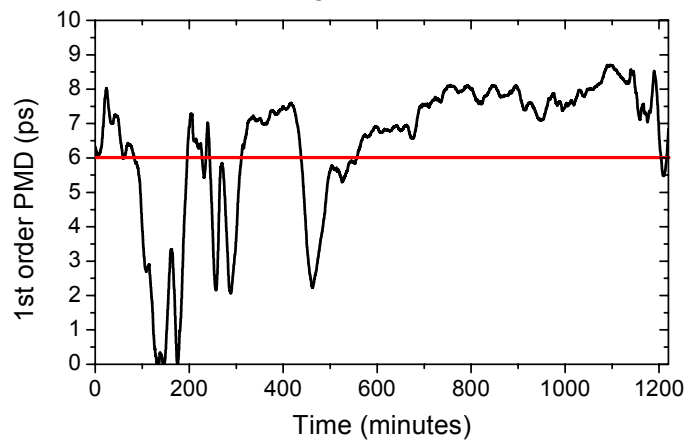

Fig. 3. Real-time trial from a PMD measurement in a $80 \mathrm{~km}$ SMF + $10 \mathrm{~km}$ DCF span. The average DGD monitored is represented by the horizontal line at 6 ps.

At measurement start, time $T=0$, the SMF fibre was placed in the $5^{\circ} \mathrm{C}$ chamber and allowed to cool for 180 minutes after which point it was removed, back to a room temperature of $22^{\circ} \mathrm{C}$. The total measurement period went over a total of 20 . hours. The rapid PMD variations in the beginning and at $T=180$ minutes thus correspond to cooling and re-heating of the fibre respectively, while the relatively steady period after $\mathrm{T}=550$ minutes corresponds to the situation where the fibre temperature has settled to room temperature. At $\mathrm{T}=1150$ the spool was again cooled and again a more rapid PMD variation is observed.

These measurements thus show a practical and realtime example of $1^{\text {st }}$ order PMD monitoring.

\section{Conclusions}

A simple PMD monitoring method requiring no changes to the transmitter has been presented. The method, is based on PMD induced SPM spectral broadening in a HNLF fibre combined with optical filtering. The technique was presented through numerical simulations, $10 \mathrm{~Gb} / \mathrm{s}$ NRZ experiments and finally a real-time PMD monitoring trial.

\section{Acknowledgements}

The work described in this paper was carried out with the support of the BONE-project ("Building the Future Optical Network in Europe"), a Network of Excellence funded by the European Commission through the $7^{\text {th }}$ ICT-Framework Programme.

\section{References}

1 J. Strand et al., IEEE Commun. Mag., Feb. 2001. 2 M. Brodsky et al., IEEE/OSA JLT, Dec. 2006.

3 J. Jiang et al., ECOC 2008, paper We.3.E.7.

4 J. L. Blows et al., ECOC 2005, paper We.2.5.7.

5 S.M.R.M. Nezam et al., CLEO 2001, pp. 561-563.

6 I.P. Kaminow et al., 'Optical Fiber Telecommunications V,' Elsevier, 2008.

7 M. Shtaif et al., PTL, 12(1), p. 53-5, 2000.

8 J. Cameron, et al., PTL, 10(9), p. 1265-1267 1998. 